\title{
Sleep Onset REM Periods in Schizophrenic Patients
}

\author{
Stephan F. Taylor, Rajiv Tandon, James E. Shipley, \\ Alan S. Eiser, and JoAnn Goodson
}

Sleep EEG studies in depression have consistently shown shortened rapid-eye-movement (REM) iatency in many patients (Kupfer et al 1986), with a smaller subset experiencing sleeponset REM (SOREM), defined as the onset of REM within 10-20 $\mathrm{min}$ of the onset of sleep. In depression, SOREMs have been associated with greater illness severity (Reynolds et al 1985; Coble et al 1981), psychotic symptoms (Coble et al 1981; Kupfer et a' 1986; Thase et al 1986), and older age (Schultz et al 1979; Ansseau et al 1984; Reynolds et al 1985; Kupfer et al 1986; Kumar et al 1987). Research to date cannot yet determine whether SOREM/s represent an extension of the same process or processes that cause shortenine of REM latency or result from a different process. Kupfer and Ehlers (1989) have suggested that SOREMs may indicate shortening of REM latency because of increased REM "pressure," as opposed to deficient slow-wave sieep, which could aiso shorten REM latency. Examination of this process in schizophrenic patients may be useful, because some schizophrenic patients, like depressed patients, exhibit shortened REM latencies, including SO-

From the Schizophrenia Program (SFT, RT, JG) and Sleep Diagnostic and Research Program (JES, ASE), University of Michigan Department of Psychiatry, 1500 East Medical Center Drive, Ann Arbor, MI 48109-0120.

Address reprint requests to Stephan F. Taylor, M.D., University of Michigan, Department of Psychiatry, 1500 East Medical Center Drive, Ann Arbor, MI 48109-0120.

Received September 13, 1990; revised December 9, 1990.

Presented at the New Research Poster Session of the 143rd Annual Meeting of the American Psychiatric Association, New York, May 12-17, 1990.
REM (Zarcone et al 1987; Kempenaers et al 1988). We undertook the following retrospective analysis of our schizophrenia-sleep data base, comparing patients who experienced SOREM periods with those who did not to see whether the groups showed differences in clinical presentation, sleep variables, or prognosis.

\section{Methods}

The sample consisted of 36 schizophrenic inpatients (mean age $=28.6 \pm 7.7$, range 1947) diagnosed by SADS/RDC and DSM-IIIR criteria who gave informed consent to participate in the study. After a minimum of 2 weeks free of medication, they underwent two consecutive nights of sleep EEG studies in their own hospital beds, with the first night for adaptation and to rule out any primary sleep disturbance, such as sleep apnea. Data from the second night only were used in the analysis. Patients were clinically screened to exclude those with signs of narcolepsy, and staff prevented patients from napping on the days when sleep studies were performed. Placement of electrodes and scoring were in accord with the methods described by Rechtschaffen and Kales (1968). Sleep onset was defined as the first minute of stage 2 sleep followed by at least $10 \mathrm{~min}$ of stage 2 sleep not interrupted by more than $2 \mathrm{~min}$ awake or in stage 1. REM latency was defined as the time between sleep onset and the occurrence of the first REM period of at least $3 \mathrm{~min}$ duraticn, minus intervening time awake (RLMA). 
Once during the medication-free period and once after 4 weeks of treatment with 8-30 mg haloperidol equivalents, patients were assessed by the Brief Psychiatric Rating Scale (BPRS), the Scale for the Assessment of Negative Symptoms (SANS), and the Hamilton Rating Scale for Depression (HRSD, 17 item). One-year follow-up was done on 27 patients and scored according to the Strauss-Carpenter Outcome Scale (Strauss and Carpenter 1972).

\section{Results}

Of the 36 patients, $6(16.7 \%)$ experienced REM latency less than $10 \mathrm{~min}$ and 1 experienced a REM latency between 10 and $20 \mathrm{~min}$. As seen in Figure 1, the distribution of REM latencies suggests a bimodal distribution. Using the strict definition of SOREM as REM onset $<10 \mathrm{~min}$, we have compared these 6 patients with SOREM with the remaining 20 patients with $R L M A \geqslant 10 \mathrm{~min}$.

The SOREM and the non-SOREM group did not differ significantly in age at the time of the study or at the onset of illness, duration of illness, number of hospitalizations, education, sex distribution, or subtype distribution (Table 1). Oniy 1 patient in the SOREM group had never been on medication, and of those who had been, 2 of 5 had been medication-free for more than 4 weeks, compared with 9 of 15 in the nonSOREM group.
Analysis of sleep variables was by MannWhitney $U$ test. With regard to measures of sleep (Table 2), the SOREM group differed from the non-SOREM group only in having a shorter first REM period and less first period REM activity. The two groups exhibited no significant differences in other measures of REM sleep, measures of sleep continuity, or sleep architecture.

Two-way analysis of variance (ANOVA) of rating scales (Table 1), with pretreatment and posttreatment scales as repeated measures, revealed a strong group effect for SANS scores (df $=1,34, p<0.005$ ). Post hoc $t$-test with degrees of freedom corrected for the disparity in sample sizes (Glantz 1987) showed greater negative symptoms pretrestment and posttreatment in the SOREM sroup. We found a group effect for BPRS total scores ( $d f=1,34, p=$ 0.05 ), but these scores did not differ by post hoc $t$-test. BPRS positive subscales (conceptual disorganization, suspiciousness, hallucinatory behavior, and unusual thought content) and HRSD scopes did not differ between the groups. ANOVA also revealed a very strong treatment effect for all scales (df $=1,34, p<0.0001$ ), and no treatment by group interaction, indicating that both groups improved equally with treatment. On the Strauss-Carpenter Outcome Scale, the SOREM group had significantly poorer global functioning at 1 year by Student's $t$-test.

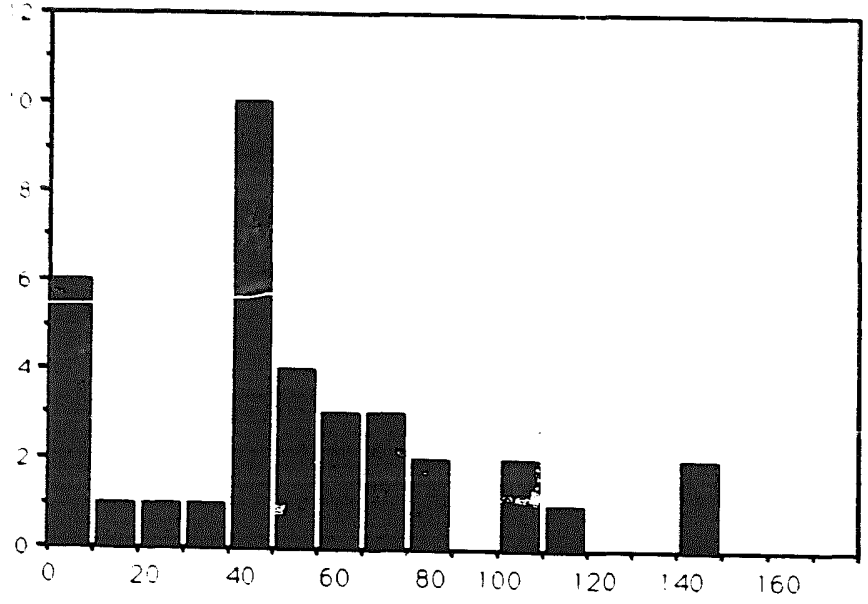

REM latency minus awake minutes
Figure 1. Frequency distributions of REM latencies in schizophrenic patients $(n=36$ patialts). 
Table 1. Characteristics of SOREM and Non-SOREM Schizophrenics

\begin{tabular}{|c|c|c|c|c|c|}
\hline Variable & $\begin{array}{c}\text { SOREM } \\
(n=6) \\
\text { Mean } \pm \text { SD } \\
\end{array}$ & $\begin{array}{c}\text { Non-SOREM } \\
(n=30) \\
\text { Mean } \pm \text { SD }\end{array}$ & $F$ & $x^{2}$ & $p<$ \\
\hline Age (yr) & $32.2 \pm 9.75$ & $27.9 \pm 7.34$ & & 1.24 & NS \\
\hline Sex & $3 \mathrm{M}, \mathbf{3 F}$ & $21 \mathrm{M}, 9 \mathrm{~F}$ & & 0.9 & NS \\
\hline Age at onset & $27.5 \pm 11.1$ & $23.0 \pm 7.1$ & & 1.29 & NS \\
\hline $\begin{array}{l}\text { Education (yr) } \\
\text { Duration of illness }\end{array}$ & $12.3 \pm 1.4$ & $13.1 \pm 2.4$ & & 0.76 & NS \\
\hline $\begin{array}{l}\text { (mo) } \\
\text { Number of }\end{array}$ & $56.8 \pm 75.5$ & $48.2 \pm 60.3$ & & 0.39 & NS \\
\hline $\begin{array}{l}\text { hospitalizations } \\
\text { Number neuroleptic }\end{array}$ & $3.3 \pm 4.1$ & $1.9 \pm 3.0$ & & 1.03 & NS \\
\hline $\begin{array}{l}\text { naive (\%) } \\
\text { DSM-IIIR subtypes }\end{array}$ & $1(16.7)$ & $15(50)$ & & 2.26 & NS \\
\hline Paranoid & 2 & 13 & & & \\
\hline Undifferentiated & 4 & 15 & & & \\
\hline Disorganized & 0 & 2 & & & \\
\hline \multicolumn{6}{|l|}{ Clinical variables } \\
\hline BPRS total & & & 4.12 & & $=0.05$ \\
\hline Pretreatment & $53.8 \pm 8.9$ & $46.2 \pm 7.6$ & & 2.17 & NS \\
\hline Posttreatment & $39.7 \pm 5.3$ & $35.4 \pm 7.1$ & & 1.39 & NS \\
\hline $\begin{array}{l}\text { BPRS positive } \\
\text { symptoms }\end{array}$ & & & 2.51 & & NS \\
\hline Pretreatment & $16.5 \pm 3.1$ & $14.3 \pm 2.7$ & & & \\
\hline Posttreatment & $11.2 \pm 2.6$ & $9.8 \pm 3.0$ & & & \\
\hline SANS & & & 12.23 & & 0.005 \\
\hline Pretreatment & $16.0 \pm 2.0$ & $11.1 \pm 4.2$ & & 2.76 & 0.05 \\
\hline Posttreatment & $12.5 \pm 3.6$ & $7.6 \pm 2.7$ & & 3.84 & 0.01 \\
\hline HRSD & & & 0.065 & & NS \\
\hline Pretreatment & $14.7 \pm 2.2$ & $13.8 \pm 4.7$ & & & \\
\hline Posttreatment & $8.5 \pm 2.7$ & $8.7 \pm 4.2$ & & & \\
\hline $\begin{array}{l}\text { Outcome: Global } \\
\text { function }{ }^{b}\end{array}$ & $7.2 \pm 3.1^{c}$ & $12.0 \pm 3.1$ & & 3.39 & 0.01 \\
\hline
\end{tabular}

For t-tests, df corrected according to Glantz (1987).

'For the non-SOREM group, $n=21$.

Higher score means better outcome.

\section{Discussion}

Our percentage of patients with SOREM (16.7\%) compares to Zarcone et al (1987), who fosind 3 of 12 schizophrenic patients (25\%) to have a RLMA of less than $15 \mathrm{~min}$. Kempenaers et al (1988) report REM latencies of less than $20 \mathrm{~min}$ in 3 of 26 patient-nights. SOREMs can occur in normals when the sleep-wake cycle is altered (Carskadon and Dement 1975) and have been described in amphetamine withdrawal, but nei- ther of these factors appearec to be operative with our patients. One has to consider the possible effects of neuroleptic withdrawal with only a 2-week washout period, although half of our SOREM patients had either never been on psychotropics or had been withdrawn for more than 4 weeks.

SOREM periods in our schizophrenic patients have relatively short durations when compared with SOREMs in depressives, which tend to be long (Ansseau et al 1984), cxcept when 
Table 2. Sleep Parameters

\begin{tabular}{|c|c|c|}
\hline \multirow[t]{2}{*}{$\begin{array}{l}\text { REM latency minus } \\
\text { awake, min }\end{array}$} & $\begin{array}{l}\text { SOREM } \\
(n=6)\end{array}$ & $\begin{array}{l}\text { Non-SOREM } \\
(n=30)\end{array}$ \\
\hline & $\begin{array}{c}\text { Mean } \pm \text { SD } \\
3.7 \pm 3.3\end{array}$ & $\begin{array}{l}\text { Mean } \pm \text { SD } \\
64.6 \pm 31.7\end{array}$ \\
\hline \multicolumn{3}{|l|}{ Sleep continuity } \\
\hline Sieep latency $(\min )$ & $70.3 \pm 60.5$ & $75.7=65.7$ \\
\hline Total time asleep ( $\mathrm{min}$ ) & $296.3 \pm 85.9$ & $307.4 \pm 80.2$ \\
\hline Arousais & $5.2 \pm 3.2$ & $4.4=4.0$ \\
\hline $\begin{array}{l}\text { Early moming } \\
\text { awakening ( } \min \text { ) }\end{array}$ & $13.5 \pm 18.3$ & $5.8 \pm 11.8$ \\
\hline Sleep efficier & $72.5 \pm 20.4$ & $74.6 \pm 17.4$ \\
\hline Sleep mainter & $90.3 \pm 12.7$ & $93.9 \pm 8.1$ \\
\hline \multicolumn{3}{|l|}{ Sleep architecture } \\
\hline Stage $1 \%$ & $13.2 \pm 6.7$ & $13.8 \pm 6.2$ \\
\hline Stage $2 \%$ & $52.1 \pm 6.5$ & $52.1 \pm 10.8$ \\
\hline Delta $\$$ & 5.9 & $10.3 \pm 11.6$ \\
\hline REM \% & 26.1 & $23.8 \pm 7.7$ \\
\hline \multicolumn{3}{|l|}{ REM sleep } \\
\hline REM periods & $3.8 \pm 1.3$ & $3.1 \pm 1.0$ \\
\hline Total REM time (min) & $76.2 \pm 22.1$ & $72.4 \pm 28.8$ \\
\hline Total REM activity & $88.3 \pm 43.7$ & $86.3 \pm 52.1$ \\
\hline Total REM density & $1.13 \pm .25$ & $1.16 \pm .47$ \\
\hline \multicolumn{3}{|l|}{ First REM period } \\
\hline Time (min) & $7.2 \pm 3.4^{a}$ & $20.4 \pm 12.4$ \\
\hline Activity & $8.3 \pm 4.6^{b}$ & $22.9 \pm 17.9$ \\
\hline Density & $1.2 \pm .55$ & $1.1 \pm .61$ \\
\hline
\end{tabular}

" $p<0.005$ by Mann-Whitney $U$ test.

$p<0.01$ by Mann-Whitney $U$ test.

psychosis accompanies the depression (Thase et al 1986; Ganguli et al 1987).

Schizophrenic patients with SOREM, compared with those without SOREM, had a shorter first REM period, more negative symptoms both before and after treatment, and poorer global functioning at 1 year. SOREMs may simply indicate greater overall severity (higher pretreatment BPRS and SANS scores and poor outcome), and that would be consistent with the demonstrated association between shortened REM latency (Tandon et al 1989) and the poor outcome associated with negative symptoms in schizophrenia (Andreasen 1982). After neuroleptic treatment, the major differences occur in ratings of negative symptoms, suggesting that additional research examine the links between persistent negative symptomatology and neurotransmitter mecha- nisms involved in the control of REM sleep onset and duration.

\section{References}

Andreasen N (1982): Negative symptoms in schizophrenia: Definition and reliability. Arch Gen Psychiatry 34:784-788.

Ansseau M, Kupfer DJ, Reynolds CF, McEachran AB (1984): REM latency in major depression: Clinical characteristics associated with sleep onset REM periods. Biol Psychiatry 19:1651-1666.

Carskadon MA, Dement WC (1975): Sleep studies on a 90-minute day. Electroencephalogr Clin Neurophysiol 39:145.

Coble PA, Kupfer DJ, Shaw DH (1981): Distribution of REM latency in depression. Biol Psychiatry 16:453-46K.

Ganguli R, R: ynolds CF, Kupfer DJ (1987): Electroencephalogr phic sleep in young, never-medicated schizoptrenics. Arch Gen Psychiatry 44:3644.

Glantz SA (1987): Primer of Biostatistics, 2nd ed. New York: McGraw-Hill, pp 77-78.

Kempenaers C, Kerkhofs M, Linkowski P, Mendlewicz (1988): Sleep EEG variables in young schizophrenic and depressive patients. Biol Psychiarny 24:833-838.

Kumar A Shipley JE, Eiser AS, et al (1987): Clinical correlates of sleep onset REM periods in depression. Biol Psychiatry 22:1477-1481.

Kupfer DJ, Ehlers CL (1989): Two roads to rapid eye movement latency. Arch Gen Psychiatiry 46:945-948.

Xupfer DJ, Reynolds CF, Grochocinski VJ, Ulrich RF, McEachran A (1986): Aspects of short REM latency in affective states: A revisit. Psychiatry Res 17:49-59.

Rechtschaffen A, Kales A (1968): A Manual of Standardized Terminology, Techniques and Scoring System for Sleep States of Human Subjects. Washington, DC: Public Health Service. US Government Printing Office.

Reynolds CF, Kupfer DJ, Taska LS, et al (1985): EEG sleep in elderly depressed, demented and healthy subjects. Biol Psychicory 20:431442.

Schulz H, Lund R, Cording C, Dirlich G (1979): Bimodal distribution of REM sleep latencies in depression. Biol Psychiatry 14:595-600.

Strauss JS, Carpenter WT (1972): The prediction of 
outcome in schizophrenia: I. Characteristics of outcome. Arch Gen Psychiatry 27:739-746.

Tandon R, Shipley JE, Eiser AS, Greden JF (1989): Association between abnormal REM sleep and negative symptoms in schizophrenia. Psychiatry Res 27:359-361.
Thase ME, Kupfer DJ, Ulich RF (1986): Electroencephalographic sleep in psychotic depression. Arch Gen Psychiatry 43:886-893.

Zarcone VP, Benson KL, Berger PA (1987): Abnormal rapid eye movement latencies in schizophrenia. Arch Gen Psychiatry 44:45-48. 